\title{
Evaluation of Effectiveness of Neonatal Resuscitation Programme (NRP) Course Among Paediatric Residents of BPKIHS
}

\author{
Yadav SK ${ }^{1}$, Bhatta NK ${ }^{2}$, Yadav SP ${ }^{3}$, Kanodia $\mathrm{P}^{4}$, Moktan $\mathrm{D}^{5}$
}

\begin{abstract}
Introduction: Neonatal resuscitation is an essential skill for neonatal care providers, especially for junior doctors who are often the first persons to attend to a newborn in need of resuscitation. The Neonatal Resuscitation Programme (NRP) training course offers a comprehensive and systematic training programme that has been adopted in 130 countries worldwide. Reports from different countries attributed the improvements in neonatal mortality and morbidity over the past two decades partly to the implementation of a systematic neonatal resuscitation training programme. The objective of this study was to evaluate the effectiveness of Neonatal Resuscitation Programme (NRP) in improving the knowledge of the paediatric resident doctors after completion of the course. Materials and Methods: This was a cross-sectional interventional study. The resident doctors who attended the NRP course were enrolled. The knowledge was evaluated by written 30 -item questionnaire pre- and post- course score. Statistical analysis was done by descriptive statistics and paired t-test. $p$-value of $<0.05$ was taken as significant. Results: Data of 18 paediatric residents who attended the course were analyzed. There were four female and 14 male residents. Out of 18 residents, eight were from first year, seven were from second year and three were from third year. Their mean scores (out of 30) were 13.84 (SD 2.57) (pre-course) and 16.68 [(SD 3.15) (post-course) ( $p=0.001)]$. Conclusions: NRP course produced a modest gain in residents' knowledge on neonatal resuscitation at the end of their course. NRP training has the potential to substantially improve knowledge of neonatal resuscitation.
\end{abstract}

Key words: Health care, Methods, Newborn, Resuscitation

\section{Introduction}

$\mathrm{T}$ he life of a foetus in utero and the independent existence of a newborn are two vastly varied conditions requiring complex transitions. Birth asphyxia contributes to $23 \%$ of the 4 million neonatal deaths worldwide every year. In addition to its contribution to mortality, birth asphyxia can result in cognitive impairment, epilepsy, cerebral palsy, and chronic diseases in later life $^{1}$. These numbers assume significance in Indian settings where neonatal mortality rate of 33 contributes to about $75 \%$ of the infant
'Dr. Sunil Kumar Yadav, DM Neonatology Resident, ${ }^{2}$ Dr. Nisha Keshary Bhatta, Professor, ${ }^{3} \mathrm{Dr}$. Shankar Prasad Yadav, Senior Resident, ${ }^{4}$ Dr. Piush Kanodia, DM Neonatology Resident, ${ }^{5}$ Dr. Deepak Moktan, Junior Resident. All from the Department of Paediatrics and Adolescent Health, BP Koirala Institute of Health Sciences, Dharan, Nepal.

Address for correspondence:

Dr. Sunil Kumar Yadav, MBBS, MD

DM (Neonatology) Resident

Department of Paediatrics and Adolescent Health Division of Neonatology

BPKIHS, Dharan

E-mail:dr.sunil_yadav@yahoo.com

Tel No: +9779817930222

\section{How to cite}

Yadav SK, Bhatta NK, Yadav SP, Kanodia P, Moktan D. Evaluation of Effectiveness of Neonatal Resuscitation Programme (NRP) Course Among Paediatric Residents of BPKIHS. J Nepal Paediatr Soc 2015;35(1):18-23.

doi: http://dx.doi.org/10.3126/jnps.v35i1.12300

This work is licensed under a Creative Commons Attribution 3.0 License.

cc) (i)

mortality rate of 47 as figures from 2010 reveal. There is similar scenario in Nepal where neonatal mortality is 24.2 and infant mortality rate is $33.6^{2}$. This contribution of neonatal mortality to infant mortality rate has been increasing over the past decade as measures to reduce infant mortality are becoming effective ${ }^{3}$. Approximately $10 \%$ of newborns (4-7 million per year) require some form of assistance at birth. This makes 
neonatal resuscitation a frequently performed medical intervention ${ }^{4,5,6}$. As per the updated (October 2010) recommendations of International Liaison Committee on Resuscitation (ILCOR), Neonatal Resuscitation Program (NRP) of American Heart Association (AHA) and American Academy of Paediatrics (AAP), at least one trained person is required to be present during delivery ${ }^{5}$. This requires that the healthcare personnel involved need to be abreast with the latest recommendations and should follow them in their clinical practice. The Indian Academy of Paediatrics (IAP) and National Neonatology Forum (NNF) of India currently follow NRP guidelines. IAP in collaboration with National Rural Health Mission of Government of India developed Basic Newborn Care and Resuscitation Programme (BNCRP) of Navjaat Shishu Suraksha Karyakram (NSSK) adopted from NRP guidelines for grass root workers as well as paediatricians ${ }^{7}$.

Neonatal resuscitation is an essential skill for neonatal care providers, especially for junior doctors who are often the first persons to attend to a newborn in need of resuscitation. The Neonatal Resuscitation Provider (NRP) training course, jointly developed by the American Academy of Paediatrics (AAP) and the American Heart Association, offers a comprehensive and systematic training programme that has been adopted in 130 countries worldwide ${ }^{8}$. Reports from different countries attributed the improvements in neonatal mortality and morbidity over the past two decades partly to the implementation of a systematic neonatal resuscitation training programme $e^{9,10,11}$. Neonatal resuscitation program guidelines (NRPG) is indeed a very effective and feasible technique during the delivery process in the reduction of neonatal mortality. It is important to disseminate widely the knowledge and technique of NRPG in places where traditional resuscitation is still being widely practiced especially in developing countries ${ }^{12,13}$. However, reports also showed that many involved in the care of newborn infants felt unprepared to perform neonatal resuscitation ${ }^{14,15,16}$. Three-quarters of all births in New South Wales (NSW) and Australian Capital Territory (ACT) take place in rural or urban non-tertiary hospitals where one-third of health personnel are inadequately trained in neonatal resuscitation and many do not feel confident in their skills. Effective neonatal resuscitation training for these areas is urgently required ${ }^{17,18,19}$.

The Neonatal Resuscitation Program (NRP), a widely adopted training program endorsed by the American Heart Association (AHA) and the American Academy of Paediatrics (AAP) ${ }^{20}$, has shown to provide good retention of knowledge in the participants ${ }^{21,22}$, but information regarding its efficacy in relation to the specialty training of the attendants is lacking. We evaluated the effectiveness of the NRP course in improving the knowledge of paediatric resident doctors in BPKIHS.

\section{Material and Methods}

This was a cross-sectional interventional study involving a cohort of 18 paediatric residents (first, second and third year) of B.P. Koirala Institute of Health Sciences (BPKIHS) which is a tertiary care centre and medical college located in eastern Nepal. It is running a seven bedded level II neonatal intensive care unit (NICU) with two neonatal ventilators. BPKIHS enrols five to eight students per year for post graduation study in department of paediatrics.

Educational Intervention: The neonatal resuscitation classes were adapted from the American Academy of Paediatrics (AAP) Neonatal Resuscitation Programme (NRP) $6^{\text {th }}$ edition. The course consisted of eight classes of one hour duration every day. The eight lessons of NRP $6^{\text {th }}$ edition were systematically taught:

i. Overview and principles of resuscitation

ii. Initial steps of resuscitation

iii. Positive pressure ventilation

iv. Chest compressions

v. Endotracheal intubation

vi. Medications

vii. Special considerations

viii. Ethics and care at the end of life.

The classes included the following components:

a. Overview lectures: using the slides from the standard NRP course, the major concepts in neonatal resuscitation were highlighted, including cardiopulmonary adaptations, apnoeas, important equipments and an overview of the NRP algorithm focusing on the initial steps in resuscitation.

b. Demonstration of key skills such as bag and mask ventilation and cardiac compression, followed by hands-on practice on the manikins.

Evaluation of effect of course on cognitive knowledge: The NRP evaluation multiple choice and fillin questions were administered for each lesson taught. The results of the 30-item questionnaire pre- and postclasses which cover all aspects of the resuscitation were used to assess change in cognitive knowledge. The pre-test was administered before the class and the post-test immediately after the class. The NRP passing 
criterion was followed for this paper and considered a score of 25.5 or above.

The test script: The standard teaching materials, including the test script, from the NRP programme were used. The multiple-choice and fill-in questions were taken from AAP/NRP $6^{\text {th }}$ edition. In the test script, there were 30 questions which were distributed as shown in Table 1.

Table 1

\begin{tabular}{|c|l|}
\hline $\begin{array}{c}\text { Question } \\
\text { number }\end{array}$ & Topic \\
\hline $1,2,3,4$ & $\begin{array}{l}\text { Overview and principles of } \\
\text { resuscitation }\end{array}$ \\
\hline $5,6,7,8,29$ & Initial steps of resuscitation \\
\hline $9,10,11,12$ & Positive pressure ventilation \\
\hline $13,14,15$ & Chest compressions \\
\hline $16,17,18$ & Endotracheal intubation \\
\hline $19,20,21,22,30$ & Medications \\
\hline $23,24,25,26$ & Special considerations \\
\hline 27,28 & Ethics and care at the end of life \\
\hline
\end{tabular}

Data were analyzed with SPSS 20 . The results were analyzed by descriptive statistics and we used paired t-test to compare the difference between preand post-test scores for resident doctors.

This study was approved by the Institutional Ethics Review Board (IERB) of BPKIHS.

\section{Results}

The entire cohort of resident doctors $(n=18)$ participated in the course, sat for the tests, and agreed to have their scores included in the research. All 18 resident doctors completed the pre-test and post-test; among them four were females and 14 were males (eight from first year, seven from second year and three from third year). Table: 2 display the mark distribution among resident doctors before and after the course. Out of 18 resident doctors, 17 (94.4\%) scored between 10-20 and one resident doctor scored less than 10 in pre-course test whereas 16 resident doctors (88.9\%) scored between 10-20 and two (11.1\%) scored between 21-30 in post-course test. Their mean scores (out of 30) were 13.84 (SD 2.57) [(pre-course) and 16.68 (SD 3.15) (post-course)] which is depicted in Table 3. The increment in mean score from 13.84 (pre-course) to 16.68 (post-course) was significant $(p=0.001)$ which is shown in Fig 1 . Though there was improvement in mean score in post-course test, no resident attained the NRP criteria for passing by scoring 25.5 or above.

Table 2: Marks distribution before and after the course

\begin{tabular}{|c|c|c|}
\hline Range of Marks ( Max & \multicolumn{2}{|c|}{ Distribution of Residents } \\
\cline { 2 - 3 } $\mathbf{3 0}$ ) & Pre course & Post course \\
\hline$<10$ & $1(5.6 \%)$ & $0(0 \%)$ \\
\hline $10-20$ & $17(94.4 \%)$ & $16(88.9 \%)$ \\
\hline $21-30$ & $0(0 \%)$ & $2(11.1 \%)$ \\
\hline
\end{tabular}

Table 3: Mean mark before and after the course

\begin{tabular}{|c|c|c|}
\hline & Mean & Standard deviation \\
\hline Pre course mark & 13.84 & 2.57 \\
\hline Post course mark & 16.68 & 3.15 \\
\hline
\end{tabular}

Figure 2 illustrates resident doctor performances in eight lessons assessed before and after the NRP course. In initial steps of resuscitation and medication (five marks in each) resident mean percentages were $66.4 \%$ and $69 \%$ respectively in post-course test.

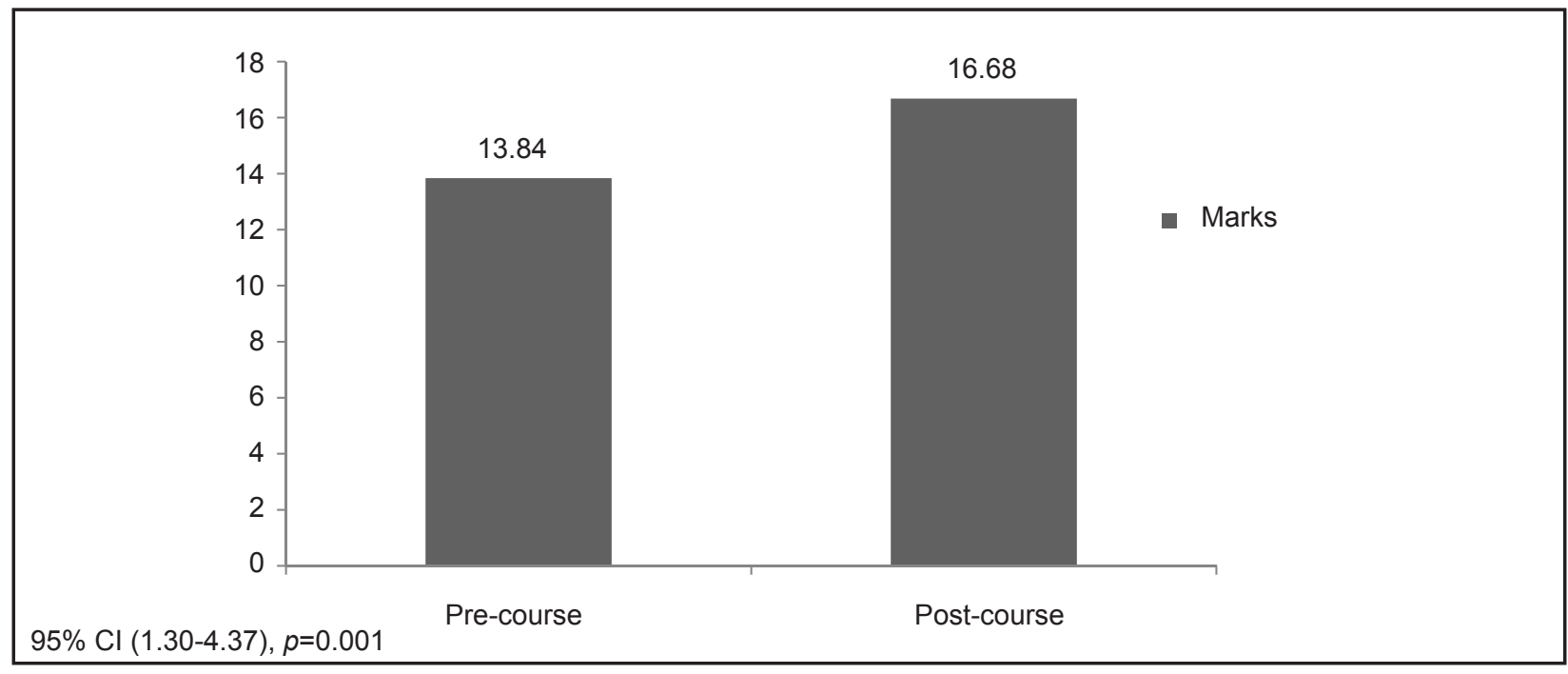

Fig 1: Mean mark before and after course 


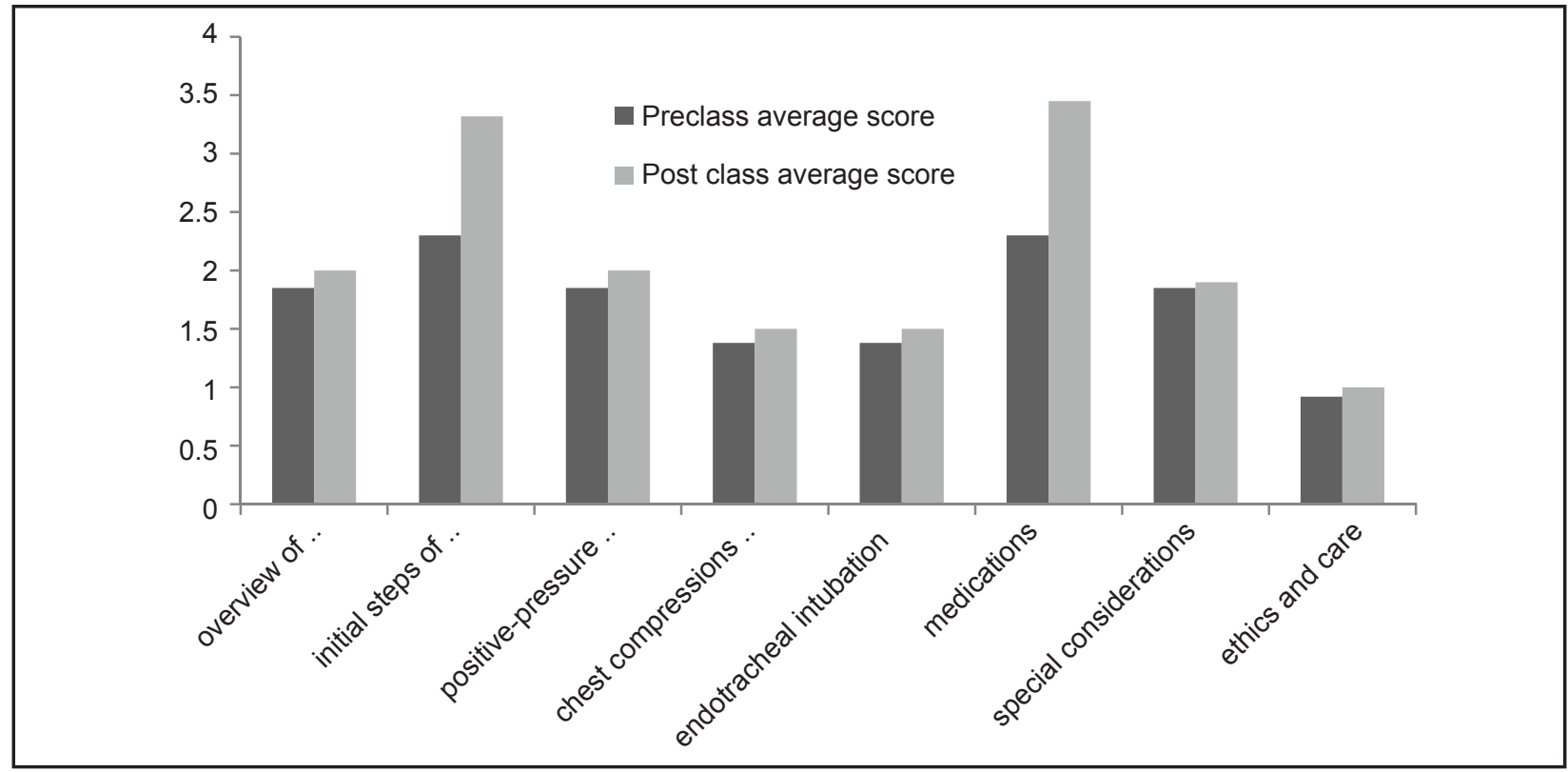

Fig 2: Mean mark before and after course in each topic assessed

\section{Discussion}

This study shows that our one-hour simulationbased neonatal resuscitation course for eight days produced a substantial learning gain immediately after the course. The overall degree of learning gain was below our expectation.

The degree of learning gain from pre- to post-tests in our study was consistent with previous studies on medical students ${ }^{23,24}$ although neither of these studies followed up the participants and assessed knowledge retention.

Questions on infant evaluation received the lowest scores compared with practical actions and theory. Possible reasons for this included the difficulties in remembering algorithms and specific clinical signs or numbers, such as the critical heart rate and the size and length of the endotracheal tube in relation to the infant's weight, and these areas deserved more emphasis in our future training classes.

The following were the strengths of this study: First, we assessed knowledge acquisition as well as short-term knowledge retention, using a test script from a well-established training programme, with questions covering three major domains in neonatal resuscitation. The format, educational resources and the delivery of our classes followed that of the NRP programme. The majority of the questions in our test scripts were related to practical aspects of neonatal resuscitation (i.e. evaluation and action), and all items in the assessment were covered in the course. Besides, identical test scripts were used for pre- and post- tests, and this minimized the issue of non-equivalence in terms of contents across different assessments.

Several limitations were noted in our study. First, we assessed only knowledge and not skills performance in the form of simulated scenarios. It was therefore unclear to what extent the knowledge demonstrated by the resident doctors was translated into actual competence. It has been shown that written test evaluation is a poor predictor of skills performance in resuscitation ${ }^{25}$. Secondly, we used a single test script with a limited number of questions for assessment. We haven't assessed the knowledge retention after months or year of completion of the course. It was unclear how much of the improvement in performances in between the tests were due to an actual gain in knowledge and how much to increased familiarity with the format of the multiple-choice questions and an improved ability to guess a correct response. Further, the test script appeared not to have been formally validated in any published report, despite that fact that it was from a well-established programme that is widely used around the world. We were also unable to perform a meaningful sample size or power estimation because there has not been a commonly accepted definition on what constitutes an educationally important learning gain in terms of neonatal resuscitation skills. Next, the resident doctors' awareness that they were part of a research project might have influenced their learning and performance. Our small sample size represented further limitations. 


\section{Conclusion}

This study demonstrates that neonatal resuscitation training classes conducted at the postgraduate level was feasible and produced a modest gain in resident doctors' knowledge on neonatal resuscitation at the end of their course, although it was unclear whether such knowledge gain would translate into a sustained and important gain in the doctors' future practice. The resident doctors' overall gain in knowledge was below our expectation. NRP training has the potential to substantially improve knowledge of neonatal resuscitation.

Acknowledgement: We are grateful to all our resident doctors who participated in the Course for agreeing to have their assessment results included as the data for this study.

Funding: None

Conflict of Interest: None

Permission from IRB: Yes

\section{References}

1. Black RE, Cousens S, Johnson HL, et al. Global, regional, and national causes of child mortality in 2008: a systematic analysis. The Lancet 2010;375:1969-987.

2. UNICEF/WHO/The World Bank/UN Pop Div. Levels and Trends in Child Mortality. Report 2013. Available from : http:// www.childinfo.org/ files/ Child_Mortality_Report_2013.pdf.

3. UNICEF, Infant and Child Mortality in India: Levels, Trends and Determinants: 2010. Available from : http://unicef.in/Uploads/Publications/Resources/ pub_doc35.pdf.

4. J. M. Perlman, J. Wyllie, J. Kattwinkel et al., "Neonatal resuscitation: 2010 International consensus on cardiopulmonary resuscitation and emergency cardiovascular care science with treatment recommendations". Pediatrics 2010:126(5): e1319-e1344.

5. J. Kattwinkel, J. M. Perlman, K. Aziz et al., "Neonatal resuscitation: 2010 American Heart Association Guidelines for Cardiopulmonary Resuscitation and Emergency Cardiovascular Care". Pediatrics 2010:126(5):e1400-e1413.

6. C. P. F. O’Donnell, P. G. Davis, and C. J. Morley, "Neonatal resuscitation: review of ventilation equipment and survey of practice in Australia and New Zealand". J Paediatr Child Health 2004:40(4):208-212.
7. B. Dhingra and A. K. Dutta, "National rural health mission," Indian J Pediatr 2011:78(12):1520-526.

8. Where NRP has been taught. IL: American Academy of Pediatrics, 2009. Available from: http://www. aap.org/nrp/intl/intl_where.html.

9. Boo NY. Neonatal resuscitation programme in Malaysia: An eight-year experience. Singapore Med J 2009;50:152-9.

10. Duran R, Aladağ N, Vatansever U, Süt N, Acunaş B. The impact of Neonatal Resuscitation Program courses on mortality and morbidity of newborn infants with perinatal asphyxia. Brain Dev 2008;30:43-6.

11. O'Hare BA, Nakakeeto M, Southall DP. A pilot study to determine if nurses trained in basic neonatal resuscitation would impact the outcome of neonates delivered in Kampala, Uganda. J Trop Pediatr 2006;52:376-9.

12. Patel D, Piotrowski ZH, Nelson MR, Sabich R. Effect of a statewide neonatal resuscitation training program on Apgar scores among high-risk neonates in Illinois. Pediatrics 2001;107:648-55.

13. Zhu XY, Fang HQ, Zeng SP, Li YM, Lin HL, Shi SZ. The impact of the neonatal resuscitation program guidelines (NRPG) on the neonatal mortality in a hospital in Zhuhai,China. Singapore Med $J$ 1997;38:485-7.

14. Carlotti AP, Ferlin ML, Martinez FE. Do our newly graduated medical doctors have adequate knowledge about neonatal resuscitation? Sao Paulo Med J 2007;125:180-5.

15. Barrie JR, Greenhalgh DL. Training in neonatal resuscitation: The views of junior paediatricians. J R Coll Physicians Lond 1993;27:151-3.

16. Bismilla Z, Finan E, McNamara PJ, LeBlanc V, Jefferies $A$, Whyte $H$. Failure of pediatric and neonatal trainees to meet Canadian Neonatal Resuscitation Program standards for neonatal intubation. J Perinatol 2010;30:182-7.

17. Lee HC, Chitkara R, Halamek LP, Hintz SR. A national survey of pediatric residents and delivery room training experience. J Pediatr 2010;157:158-61.

18. Teale KF. SHOs: The lost tribes. Training inadequate in paediatric resuscitation. BMJ 1994;308:275.

19. Foster K, Craven P, Reid S. Neonatal resuscitation educational experience of staff in New South Wales and Australian Capital Territory hospitals. J Paediatr Child Health 2006;42:169.

20. Bloom R, Cropley C. Textbook of neonatal resuscitation. 4th ed. Elk Grove Village, IL: 
American Heart Association, American Academy of Pediatrics; 2000.

21. Trevisanuto D, Ibrahim SA, Doglioni N, Salvadori $\mathrm{S}$, Ferrarese $\mathrm{P}$, Zanardo V. Neonatal resuscitation courses for pediatric residents: comparison between Khartoum (Sudan) and Padova (Italy). Pediatr Anesth 2007;17:28-31.

22. Ergenekon E, Koc E, Atalay $\mathrm{Y}$, et al. Neonatal resuscitation course experience in Turkey. Resuscitation 2000;45:225-27.
23. Bhat BV, Biswal N, Bhatia BD, Nalini P. Undergraduate training in neonatal resuscitation -A modifi ed approach. Indian J Matern Child Health 1993;4:87-8.

24. Bhatia BD, Bhat BV, Dey AK, Mohan PV. Training of final year MBBS students in neonatal resuscitation. Indian Pediatr 1993;30:113-15.

25. Rodgers DL, Bhanji F, McKee BR. Written evaluation is not a predictor for skills performance in an Advanced Cardiovascular Life Support course. Resuscitation 2010;81:453-6. 